\title{
Detection and identification of geometric forms using peripheral and central viewing'
}

\author{
STEPHEN HANDEL ${ }^{2}$ AND RICHARD E. CHRIST \\ KANSAS STATE UNIVERSITY
}

Two tasks, using identical geometric forms, compared nasal peripheral, temponal peripheral, and central viewing. In the first task, using a yes-no confidence rating scale procedure, four Ss judged the presence or absence of a known geometric form (detection). In the second task, the same Ss judged which of several known forms was presented (identification). The major result is that nasal and temporal peripheral viewing are similar and that both peripheral regions differ from central viewing. Also, detection and identification are relatively independent processes; the ease of detection of a form does not predict the ease of identification of that form.

Previous work comparing nasal and temporal peripheral viewing (Wyke \& Ettlinger, 1961; Crovitz \& Daves, 1962; Wyke \& Chorover, 1965) have led to conflicting results. This is not surprising since each study used a different set of experimental conditions (e.g., stimuli, tasks, viewing positions, methods of stimulus presentation). Nasal and temporal peripheral viewing of the same stimuli have not been compared using different tasks and rarely has peripheral viewing been compared with central viewing. Therefore, this experiment attempted to generalize previous work by comparing performance in the detection and identification of the same geometric forms using nasal peripheral, temporal peripheral, and central viewing.

\section{Detection Tak}

In the detection task, $\mathrm{S}$ judged simply the presence or absence of one known geometric form. A yes-no confidence rating scale procedure was used to generate an ROC curve. This procedure yielded a measure of the detectability of the form unaffected by S's response bias. Although signal detection theory was originally developed for auditory detection, Nachmias and Steinman (1963), and Lee (1965) have demonstrated its applicability to visual detection tasks.

\section{Identification Tack}

In the identification task, one of a set of known stimuli was presented, and $\mathbf{S}$ judged which stimulus was presented. Previous work (Whitmer, 1933; Munn \& Geil, 1932; Collier, 1931) has shown that in peripheral viewing, triangles and squares are easier to identify than circles. Casperson (1950) has shown that identification in central viewing is quite complex; factors such as perimeter, area, and length of maximum dimension differentially affect identification of geometric forms.

Detection, in a logical sense, is the first step in identification (Kaswan \& Young, 1963). In detection, $S$ judges whether or not a stimulus was presented; in identification, $S$ judges, given that a stimulus was presented, which of several alternatives he has viewed. Therefore, it can be hypothesized that the ease of detection of a form should be correlated with the ease of identification of that form. However, if detection and identification are relatively independent processes, there should be no simple relationship between the ease of detection of a form and the ease of identification of that same form.

\section{Apparatus \\ METHOD}

The stimuli and fixation point were exposed in an Iconix Model 6131 three-field tachistoscope, driven and controlled by solid state equipment. Both the fixation and stimulus fields were $6 \mathrm{in}$. wide and $4.5 \mathrm{in}$. high. The ground luminance of both fields was $.13 \mathrm{ml}$. The S's head was held in a rigid position by means of a bite-bar attached to the tachistoscope. The left eye was occluded. The $\mathrm{S}$ was 57.3 in. from the stimuli. Therefore, inches on the stimulus cards are equivalent to visual angles (e.g., 2 in. are equivalent to 2 deg).

The $S$ responded by using a two-throw toggle switch and five push buttons (arranged in a semicircle) mounted on a chassis box. The toggle switch and push buttons activated lamps mounted on E's monitor panel. The tachistoscope, response panels, $S$, and $E$ were in a sound-shielded room that was dark except for a small light used by $E$ for changing stimuli and monitoring $S$ 's performance.

\section{Viewing Position}

Three viewing positions were used for stimulus presentation: central, $4.75 \mathrm{deg}$ to the temporal side, and $4.75 \mathrm{deg}$ to the nasal side.

When the stimuli were presented centrally, the fixation point was placed in the center of the visual field and the stimulus was also placed in the center of the field (no problems with masking were encountered). When the stimuli were presented in the temporal periphery, the fixation point was placed 2.375 in. to the left (nasal) of the center of the field, and the stimulus was placed 2.375 in. to the right of the center. Thus, presentation was at a total of $4.75 \mathrm{in}$. (4.75 deg) to the temporal side of the viewing field. The reverse procedure was used for nasal presentation.

\section{Stimuli}

The five forms were a circle, two equilateral triangles, one with the apex pointing upwards and the other with the apex pointing downwards, and two open triangles (" $V$ " shapes) formed by removing the horizontal sides of the equilateral closed triangles. The circle had an outside diameter of $.29 \mathrm{in}$. and the open and closed triangles had sides that measured .29 in. The fixation points consisted of two horizontal and two vertical crosshairs .375 in. long terminating at the circumference of an imaginary circle with a 1.31 in. diam. The width of all lines was .033 in.

The forms and fixation points were drawn on vellum paper, photographically reduced, made into $6 \times 8$ in. matte prints, and mounted on cardboard. The reflectance of the matte paper was $80 \%$ and the reflectance of the black lines of the forms and fixation points was $2.5 \%$.

There were 15 form cards and 3 fixation point cards, five forms, and one fixation point for each viewing position. One additional card, a blank field created by photographing a blank sheet of vellum paper, was used for the detection task.

Subjects

The two authors and two graduate students served as Ss. All Ss 
had normal visual acuity and were righteye dominant. All Ss had served in previous studies and were familiar with both the apparatus and stimuli.

\section{Procedure $^{3}$}

Prior to the experimental sessions, the exposure times were varied for both the detection and identification task in order to achieve a criterion performance. When performance had stabilized using one exposure time to this criterion, the experimental sessions began. Also, the order of presentation of conditions for both tasks was counterbalanced. This proved unnecessary as little improvement in performance was found.

Before each session, $S$ stayed in a dark room for $15 \mathrm{~min}$ to dark adapt.

Detection. Each session of the detection task consisted of a random sequence of 60 stimulus-form trials and 60 blank-field trials. Only one stimulus form and one viewing position were used in a given session and $\mathbf{S}$ knew this before the session began. Each session took about $15 \mathrm{~min}$. Several sessions were run per day until a total of 30 sessions had been run per S; there were two replications of each stimulus form by viewing position combination. A different random order was used in each session.

The exposure times necessary for $80 \%$ correct detections for each viewing position were determined separately for each $S$. These values, for different $\mathrm{Ss}$, ranged from 60 to $75 \mathrm{msec}$ for peripheral viewing and from 35 to $50 \mathrm{msec}$ for central viewing. The same exposure time for each $S$ was used for nasal and temporal presentation. In the actual experimental sessions, there were 82,75 , and $85 \%$ correct detections for nasal, temporal, and central viewing, respectively.

To begin a trial, E would push a start button which activated the warning tone for $1 \mathrm{sec}$. Two seconds after this tone terminated, the stimulus field was exposed. The $S$ would then respond with the toggle switch to indicate whether or not he saw the stimulus and with one of the five push buttons to indicate his confidence, ranging from a guess to absolute certainty. After recording S's response, E would initiate the next trial.

Identification. For the identification task, 75 trials consisting of a random sequence of the five forms (each form occurring 15 times) constituted one block of trials at one of the three viewing positions. Two such trial blocks, each at a different viewing position, were run during one session. Each session lasted about $25 \mathrm{~min}$ with a $5 \mathrm{~min}$ rest between trial blocks. Eighteen sessions were completed by each $S$, six at each of the three viewing positions. A different random order of forms was used for each trial block. The $S$ responded by pushing the button that corresponded to the form he thought he saw during the stimulus exposure.

The exposure times necessary to yield about $50 \%$ correct identifications at each viewing position were determined separately for each $S$. These values ranged from 90 to $100 \mathrm{msec}$ for nasal and temporal viewing and from 45 to $55 \mathrm{msec}$ for central viewing. 4 The same exposure time for each $S$ was used for nassl and temporal viewing.

\section{Detection Takk}

\section{RESULTS}

The area under an ROC curve was the measure of the detectability of a form; +.50 indicates chance detection and +1.0 indicates perfect detection. The area under the ROC curve, discussed in Green and Swets (1966), provides a simple distribution-free index of the detectability of a signal.

The ratings were used to construct an ROC curve for each geometric form by viewing position by $S$. The areas were then averaged across Ss. The forms and the average area under the ROC curve for each form at each viewing position are shown in the first two columns of Table 1 .
Table 1

Performance in the Detection and Identifcation Tasks

\begin{tabular}{|c|c|c|c|c|c|}
\hline \multirow[b]{3}{*}{$\begin{array}{l}\text { Viewing } \\
\text { Position }\end{array}$} & \multirow[b]{3}{*}{ Stimulus } & \multicolumn{4}{|c|}{ Task } \\
\hline & & \multirow{2}{*}{$\begin{array}{l}\text { Detection } \\
\text { Area under } \\
\text { ROC curve }\end{array}$} & \multicolumn{3}{|c|}{ Identification } \\
\hline & & & $\begin{array}{c}\text { Correct } \\
\text { Identifications (c) }\end{array}$ & $\begin{array}{c}\text { Response } \\
\text { Frequency (f) }\end{array}$ & $\mathrm{c} / \mathrm{f}$ \\
\hline \multirow{5}{*}{ Nasal } & 0 & 90 & 249 & 395 & 63 \\
\hline & $\Delta$ & 91 & 212 & 392 & 54 \\
\hline & $\nabla$ & 84 & 210 & 407 & 52 \\
\hline & $\wedge$ & 73 & 156 & 300 & 52 \\
\hline & $\vee$ & 77 & 156 & 306 & 51 \\
\hline \multirow{5}{*}{ Central } & 0 & 90 & 201 & 342 & 59 \\
\hline & $\Delta$ & 84 & 169 & 380 & 44 \\
\hline & $\nabla$ & 87 & 191 & 382 & 50 \\
\hline & $\wedge$ & 90 & 169 & 321 & 53 \\
\hline & $\vee$ & 91 & 212 & 375 & 57 \\
\hline \multirow{5}{*}{ Temporal } & 0 & 82 & 261 & 441 & 59 \\
\hline & $\Delta$ & 84 & 167 & 353 & 47 \\
\hline & $\nabla$ & 81 & 189 & 352 & 54 \\
\hline & $\wedge$ & 71 & 165 & 367 & 45 \\
\hline & V & 68 & 152 & 287 & 53 \\
\hline
\end{tabular}

There was a significant difference in the detectability among forms using nasal viewing $[F(4,12)=14.4, p<.001]$. The circle and the two closed triangles were easier to detect than either of the open triangles ( $t$ tests, $\mathrm{df}=3$ ). There was also a significant difference in the detectability among forms using temporal viewing $[F(4,12)=7.7, p<.005]$; the two closed triangles and circle were again easier to detect than the two open triangles. However, there was no difference in detectability among forms presented centrally.

The rank order of the detectability of forms using nasal and temporal viewing was essentially the same (Spearman $r=+.90$, $\mathrm{p}<.05$ ), although forms presented in the nasal periphery were easier to detect than forms presented in the temporal periphery $[t(4)=7.0, p<.01]$.

\section{Identification Tack}

For each $S$, a 5 by 5 confusion matrix was tabulated; the rows were stimuli and the columns responses. Each geometric form was presented equally often so that the sum of each row was the same, but the number of times each form was used as a response differed. Deviation from an equal distribution of responses reflects a response bias.

Correct identifications. The number of correct identifications, the number of times each form was used as a response, and the ratio of the correct identifications of each form to the frequency of response of that form, averaged across Ss for each viewing position, are shown in Table 1 . This ratio removes the response bias and is an estimate of the probability of correctly identifying a form given that a response of this type was made.5

The corrected data showed that the circle was identified best at all viewing positions, but the ease of identification of the closed and open triangles is a function of the viewing position. For central viewing, the open triangles were easier to identify than the closed triangles. At the temporal periphery, the closed and open triangles with the apex pointing downwards were easier to identify. At the nasal periphery, there was little difference in the ease of identification among the two closed and two open triangles.

Identification errors. Directed graphs of the identification 
NASAL

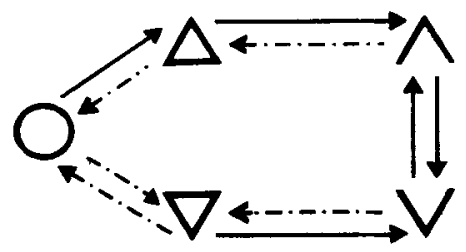

CENTRAL
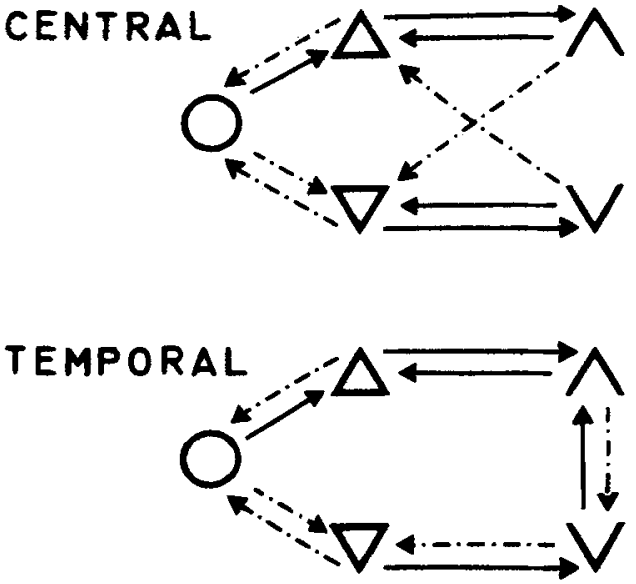

Fig. 1. Directed graphs of the incorrect identifications. The arrows point to the most frequent (solid arrow) and second most frequent (dached arrow) incorrect response when the form at the arrow base was the stimulus.

errors for each viewing position are shown in Fig. 1. The solid arrow points to the form most often incorrectly identified as the stimulus form, and the dashed arrow points to the form that was second most frequently incorrectly identified as the stimulus form. Averaged across all forms, viewing positions, and Ss, the most frequent error accounted for $39 \%$ of the total errors, and the second most frequent error accounted for $26 \%$ of the total errors.

The errors, if a circle or one of the closed triangles was the stimulus, were identical for all viewing positions: (a) a circle was incorrectly identified as a closed triangle; (b) a closed triangle was most often incorrectly identified as an open triangle with the same orientation, and less frequently as a circle.

The incorrect identifications of the open triangles differed for central and peripheral viewing. For central viewing, the open triangle was most often incorrectly identified as a closed triangle with the same orientation and less frequently as a closed triangle with the opposite orientation. In either peripheral viewing position, the open triangle was most frequently incorrectly identified as the other open triangle (with one exception) and less frequently as the closed triangle with the identical orientation.

\section{DISCUSSION}

The major conclusion of these experiments was the similarity in form detection and identification for nasal and temporal viewing and the difference between peripheral and central viewing. This conclusion is clearest for the detection task. The rank order correlation of the detectability of the forms between nasal and temporal viewing is +.90 , but the correlation between temporal and central viewing is -.63 , and between nasal and central viewing, -.78 . In the identification task, the circle was easiest to identify for all viewing positions, but the ease of identification of the closed and open triangles differed for each viewing position. However, confusions in the identification task again demonstrated the similarity between nasal and temporal viewing and their dissimilarity to central viewing.

There is no simple relationship between the ease of detecting the presence of a form and the ease of identifying that form. The detectability of a form does not predict any of the three meastires of the identification task shown in Table 1 or the pattem of incorrect identifications. In addition, in the detection task, forms presented in the nasal periphery were easier to detect than those presented in the temporal periphery. But, in the identification task, both viewing positions produced equal performance. Therefore, the initial detection of a form and the subsequent identification of that form may be relatively independent processes.

\section{REFERENCES}

CASPERSON, R. C. The visual discrimination of geometric forms. Journal of Experimental Psychology, 1950, 40, 668-681.

COLLIER, R. M. An experimental study of form perception in indirect vision. Joumal of Comparative \& Physiological Psychology, 1931, 11, 281-290.

CROVITZ, F. H., \& DAVES, W. Tendencies to eye movement and perceptual accuracy. Joumal of Experimental Psychology, 1962, 63, 495-498.

GREEN, D. M., \& SWETS, J. A. Signal detection theory and psychophysics New York: Wiley, 1966.

KASWAN, J., \& YOUNG, S. Stimulus exposure time, brightness, and spatial factors as determinants of visual perception. Journal of Experimental Psy chology, 1963, 65, 113-123.

LEE, W. ROC curves for recognition of visual patterns. Psychonomic Science, 1965, 2, 51-52.

MUNN, N. L., GEJL, G. M. A note on peripheral form discrimination. Journal of General Psychology, 1931, 5, 78-88.

NACHMIAS, J., \& STEINMAN, R. M. Study of absolute visual detection by the rating scale method. Journal of the Optical Society of America, $1963,53,1206-1213$.

WHITMER, C. A. Peripheral form discrimination under dark adaptation. Journal of General Psychology, 1933, 9, 405-419.

WYKE, M., \& ETTLINGER, G. Efficiency of recognition in left and right visual fields. Archives of Neurology, 1961, 5, 659-665.

WYKE, M., \& CHOROVER, S. L. Comparison of spatial discrimination in the temporal and nasal sectors of the monocular visual field. Perceptual \& Motor Skills, 1965, 20, 1037-1045.

\section{NOTES}

1. This research was supported by NASA University Sustaining Grant NsG-692.

2. Address: Department of Psychology, Anderson Hall, Kansas State University, Manhattan, Kansas 66502.

3. We are grateful to Mrs. D. S. Ricketson for collection and tabulation of the data.

4. An additional condition for central viewing was run using exposure durations between $50-55 \mathrm{msec}$. Using these exposare durations, $68 \%$ of the identifications were correct. The results, in terms of the rank ordering of forms, was identical for all measures in both central viewing conditions.

5. This ratio is the simplest correction procedure. The standard procedure (Green \& Swets, 1966, p. 129) yields the identical rank-order of ease of identification at each viewing condition.

(Accepted for publication January 9. 1969.) 